\title{
ENGLISH-RUSSIAN HYBRID WORDS IN TRANSLATED TEXT: ON LINGUISTIC INTERFERENCE AND NORMS OF TRANSLATION ${ }^{1}$
}

\author{
Liliya A. Nefedova \\ Chelyabinsk State University, Chelyabinsk, Russia \\ Ekaterina S. Krasnopeyeva \\ Chelyabinsk State University, Chelyabinsk, Russia
}

\begin{abstract}
The article discusses the influence of Russian-English functional bilingualism of IT and tech specialists on the formation of translation norms in the corresponding field. The research is carried out within the framework of sociology of translation and descriptive approach in translation studies. It investigates the patterns in the usage of hybrid lexemes combining Russian and English graphemes, e.g. IоT-устройство (IoT-device), API-интерфейс (API-interface) and Open Source-приложение (open source application) in translations. Methodologically, the study resorts to the theoretical stance of sociology of translation, namely the concepts of translation norm, represented in the works by G. Toury and A. Chesterman, translator's habitus and the field of translation, as well as corpus-based methodology. It utilizes a comparable corpus of translated and non-translated articles published by Russian IT business magazines itWeek, Computerworld and Novosti Elektroniki (Electronics News) in 2017. Hybrids are shown to be more common in non-translated text, which can be viewed as an aspect of the expectancy norm. Qualitative study revealed the following patterns in hybrid usage in translation. Most of the hybrids used in translation are the direct result of the transfer of original English analytical structures. Hybrids are also used in translation as part of pragmatic positive interference, which shows the translator's reliance on the recipient's extensive background knowledge of the subject, as well as command of the English language. Interference, both positive and negative, is argued to be the aspect of the expectancy norm present in the field of technology-oriented media translation.

Key words: interference, bilingualism, globalisation, socilolgy of translation, norm of translation, corpusbased translation studies, hybrid words, English-Russian hybrid words.

Citation. Nefedova L.A., Krasnopeyeva E.S. English-Russian Hybrid Words in Translated Text: On Linguistic Interference and Norms of Translation. Vestnik Volgogradskogo gosudarstvennogo universiteta. Seriya 2. Yazykoznanie [Science Journal of Volgograd State University. Linguistics], 2020, vol. 19, no. 4, pp. 86-98. (in Russian). DOI: https://doi.org/10.15688/jvolsu2.2020.4.8
\end{abstract}

УДК 81’25:316

Дата поступления статьи: 21.08.2019

ББК 81.18

Дата принятия статьи: 28.04.2020

\section{АНГЛО-РУССКИЕ ГИБРИДНЫЕ ОБРАЗОВАНИЯ В ТЕКСТЕ ПЕРЕВОДА: О МЕЖЪЯЗЫКОВОЙ ИНТЕРФЕРЕНЦИИ В КОНТЕКСТЕ ПЕРЕВОДЧЕСКИХ НОРМ ${ }^{1}$}

\author{
Лилия Амиряновна Нефёдова \\ Челябинский государственный университет, г. Челябинск, Россия \\ Екатерина Сергеевна Краснопеева \\ Челябинский государственный университет, г. Челябинск, Россия
}

Аннотация. В статье с позиций социологии перевода и дескриптивного подхода в переводоведении обсуждается вопрос формирования переводческих норм в условиях русско-английского функционального 
билингвизма специалистов сферы информационных технологий и электроники. В качестве теоретико-методологической базы выступает концепция нормы в трактовке Г. Тури и Э. Честермана. Динамика норм показана на примере результатов количественного и качественного исследования употребления гибридных образований вида IoT-yстройство, API-интерфейс и Open Source-приложение в составленном авторами корпусе переводных и непереводных материалов отраслевых изданий «itWeek», «Computerworld» и «Новости электроники», выпущенных в 2017 году. Выявлено, что дефисные гибридные образования преобладают в изученных непереводных текстах. Установлено, что в переводных текстах гибридные образования создаются как при калькировании аналитических конструкций оригинального текста - межъязыковой интерференции, так и по инициативе переводчика, ориентирующегося на норму ожидания - предпочтения реципиента-специалиста, не только обладающего специальными знаниями, но и готового к восприятию текста с большой плотностью англицизмов. Полученные данные позволили интерпретировать толерантность к интерференции и трансференции как аспект современной переводческой нормы, применяемой к текстам об информационных технологиях и электронике.

Ключевые слова: интерференция, билингвизм, глобализация, социология перевода, норма перевода, корпусное переводоведение, сложные гибридные образования, англо-русский гибрид.

Цитирование. Нефёдова Л. А., Краснопеева Е. С. Англо-русские гибридные образования в тексте перевода: о межъязыковой интерференции в контексте переводческих норм // Вестник Волгоградского государственного университета. Серия 2, Языкознание. - 2020. - Т. 19, № 4. - C. 86-98. - DOI: https://doi.org/10.15688/ jvolsu2.2020.4.8

\section{Введение}

Под влиянием английского языка как lingua franca семиотический и дискурсивный репертуар носителей национальных языков расширяется. Множественные исследования иллюстрируют рост англо-русского билингвизма в профессиональных областях, развитие которых связано с глобализацией. В сфере информационных технологий (далее - ИТ), банковском секторе, сфере продаж и других английский язык, по словам Е.С. Гриценко и Т.А. Ненашевой, «становится индексом профессиональных знаний и компетенций» [Гриценко, Ненашева, 2017, с. 37]. Наличие большого количества адаптированных и неадаптированных англицизмов в русскоязычном бизнес-дискурсе признается фактом. Так, специалисты сферы телекоммуникаций отмечают, что поскольку отраслевая терминология просто не имеет эквивалентов в русском языке, «самый удачный подход к работе - привыкнуть к неизбежному использованию иностранных слов» [Аджемова, Гарстенауэр, 2017, с. 184].

В условиях становления глобального английского языка и усиления языковых контактов неизбежны проявления межъязыковой интерференции. А.В. Кирилина рассуждает о феномене «наивного переводчика / адаптатора», в повседневности активно использующего лексические и синтаксические кальки анг- лоязычных конструкций. Задача практики «наивного перевода» - миновать процесс кодирования для экономии ментальных усилий, что в итоге приводит к сглаживанию различий между языками [Кирилина, 2011, с. 3238]. Результатом экономии ментальных усилий называют также употребление лексики в латинской графике и неадаптированных англоязычных заимствований в коммуникативном пространстве русского языка. По словам И.В. Анненковой, «это явление... пустило свои корни на уровне речевого поведения носителей русского языка... Латинская графика, выполняя важные функции точности и адекватности передачи информации адресату, экономии языковых средств, несет в себе еще и мощный заряд развития собственно русского языка» [Анненкова, 2008, с. 44].

Повсеместное распространение цифровой среды, где обесцениваются традиционные понятия языковой общности и языковой группы, размываются границы речевых норм и национальных языков, способствует гибридизации дискурсов: «...языки в новых условиях коммуникации и интенсивного веб-обмена теряют чувствительность к своей традиционной, закрепленной в словарях нормативной основе» [Загидуллина, 2018, с. 68]. Медиатизированная коммуникация ведет к становлению состояния истинного языкового и культурного суперразнообразия [Varis, Wang, 2011]. В связи с этим ученые предлагают рассмат- 
ривать вопросы языковой нормы и креатива с позиций концепции транслингвальности (translanguaging) [García, Wei, 2014, p. 21], толкуемой как «плавный синергетический переход от одной лингвокультуры к другой, в результате чего происходит некоторое их слияние, при этом отсутствует полная ассимиляция и сохраняется лингвокультурная идентичность пользователей языков, а также создается смешанный дискурс» (определение С. Канараджа, цит. по: [Прошина, 2017, с. 160]).

При этом переводоведческая проблематика остается недостаточно разработанной в научном дискурсе о глобальной динамике языков и культур [Grin, 2017, p. 156], поскольку перевод традиционно определяется как вид языкового посредничества, где границы национальных языков (named languages, по Ф. Грину [Grin, 2017, p. 156]) относительно прозрачны. Соответственно, существует необходимость в разработке методик, приемов и подходов к изучению «сдвигов в общеязыковой и переводческой нормативности» [Ривлина, 2018, с. 47]. М. Албл-Микаса фиксирует формирование отдельного направления исследований (автор объединяет их под названием ITELF - interpreting, translation and English as a lingua franca), затрагивающих следующие вопросы взаимодействия глобального английского языка и практики межъязыкового перевода: особенности устного и письменного перевода текстов, составленных на различных вариантах глобального английского языка (World Englishes); дидактика перевода текстов, отражающих различные варианты глобального английского языка; изменение социального статуса переводчика и др. [AlblMikasa, 2017, p. 369]. Вероятно, в проблемное поле ITELF возможно интегрировать и аспекты трансформации практики перевода на национальные языки в условиях «глобанглизации» (см., например: [Власенко, 2008; Орёл, 2008, 2010; Ривлина, 2018]).

В данной статье мы обращаемся к вопросу формирования переводческих норм в условиях русско-английского функционального билингвизма. С опорой на положения социологии перевода и дескриптивного подхода в переводоведении представляем рассуждение о роли английского языка как lingua franca в трансформации практики перевода на русский язык, а также иллюстрируем теоретические положения результатами частного сравнительно-сопоставительного исследования особенностей употребления слов-гибридов с элементом в латинской графике вида IoT-yстройcтво, PIN-код, Bluetooth-модуль в переводных и непереводных текстах изданий, посвященных ИТ и электронике.

\section{Материал и методы исследования}

Одним из ключевых инструментов дескриптивного подхода к исследованию переводческой деятельности признается концепция норм перевода - объяснительных гипотез, аналитических конструктов, позволяющих интерпретировать фиксируемые в тексте перевода закономерности и строить рассуждение о мотивированности переводческих решений [Chesterman, 2016, p. 109]. Нормы локальны и обусловлены культурным и историческим контекстом. Они постигаются индивидом в процессе социализации, при этом могут соблюдаться или же сознательно нарушаться в каждой конкретной ситуации перевода [Chesterman, 2016, p. 82]. Перевод, в свою очередь, понимается как деятельность, определяемая нормами (a normgoverned activity) [Toury, 2012, p. 61].

Заимствованная из методологического аппарата социологии концепция норм позволяет говорить о переводчике как об игроке в социальном поле, а перевод определять как социокультурную практику и «важный социальный фактор, несущий на себе печать места, времени, условий своего создания и влияющий на эти место, время и условия; иными словами, перевод - это социальный акт» [Тюленев, 2004, с. 106]. В соответствии с подходом П. Бурдьё нормы, традиции и культурные коды - это элементы внутри социальных полей (полей символического производства), участвующие в формировании их динамики [Bourdieu, Wacquant, 1992]. Однако в свете того, что перевод - «пограничная структура» [Тюленев, 2012, с. 116], вопрос природы данных норм остается открытым ("the question of the agency behind norms in general and behind translational norms in particular, begs for an answer") [Simeoni, 1998, p. 6]. 
Э. Честерман, опираясь на подход Г. Тури, выделяет две обширные категории переводческих норм: профессиональные нормы (professional norms) и нормы ожидания (потенциального реципиента) (expectancy norms) [Chesterman, 2016, p. 62-65]. Первые формируются под воздействием вторых и непосредственно подчинены им [Chesterman, 2016, p. 62-65]. Таким образом, можно заключить, что переводчик по определению является агентом двух полей практики: поля, которое можно условно назвать полем рецепции перевода, а также непосредственно поля практики перевода, агенты которого - профессиональные переводчики, преподаватели, критики и другие специалисты.

Д. Симеони, одним из первых предложивший рассматривать перевод сквозь призму социологии П. Бурдьё, сделал акцент на необходимости внедрения габитусного измерения в исследования переводческой деятельности [Simeoni, 1998]. Как отмечает Э. Прунч, габитус «является социокогнитивным конструктом и представляет собой интериоризированные индивидом правила и нормы поведения в поле. Он является отражением и прототипом взаимодействий между группами или классами внутри определенного поля» [Прунч, 2015, c. 362]. Д. Симеони рассуждает о традиционной нестабильности поля перевода (и относительной невозможности его выделения) и заключает, что «настройка» габитуса переводчика происходит не в поле перевода, а в поле символического производства (например, образования, медиа, литературы, науки и пр.) [Simeoni, 1998, p. 17-20] - в поле, которое мы назвали полем рецепции перевода.

Сегодня эта позиция становится как никогда актуальной в связи с появлением перевода, выполняемого билингвами без специальной подготовки (например, любительский и пользовательский перевод в цифровых пространствах), а также с активным распространением постредактирования машинного перевода. Независимо от того, кем выполнена работа (переводчиком-любителем или профессионалом), перевод как вид социальной практики осуществляется с соблюдением языковых и поведенческих норм, определяемых динамикой поля, в котором перевод выполняется, в том числе онлайн-полей, формируемых социальными сетями (подробнее об этом см.: [Krasnopeyeva, 2018]). Взаимодействие перечисленных факторов приводит к состоянию профессионального поля перевода, описанному С. Тюленевым как in statu nascendi - стадия становления [Tyulenev, 2014, p. 78].

Тем не менее на современном этапе происходит активное формирование поля «индустрии перевода». Об этом свидетельствует процесс его именования - закрепления таких терминов, как «индустрия» (language services industry), «отрасль», «перевод как бизнес», в совокупности с появлением специализированных цифровых инструментов [Remkhe, Nefedova, Gillespie, 2017], выходом на поле новых игроков (крупных переводческих компаний), а также укреплением профессиональных сообществ (в России - Союз переводчиков России, Национальная лига переводчиков и др.). Это поле характеризуется определенной динамикой, социальными позициями и профессиональными нормами, оказывающими влияние на другие поля. Например, реклама, техническая документация, а также непосредственно продукция различных отраслей могут создаваться с учетом требований локализации. Кроме того, сегодня практика профессионального перевода во многом институционализирована не только благодаря работе профессиональных организаций, но и благодаря заключению норм ожидания в "рекомендуемые нормы» («recommendable norms», по Э. Честерману [Chesterman, 2016]) - в руководства по стилю для конкретных проектов / заказчиков. Для вхождения в такое профессиональное поле требуется некоторый объем культурного капитала и специализированный профессиональный габитус.

Возвращаясь к концепции норм, подчеркнем следующие ключевые положения. Переводчики не только соблюдают нормы, но и участвуют в их формировании («translators govern norms as much as their behaviour is governed by them» [Simeoni, 1998, p. 24]). Hopмы ожидания динамичны, именно они отражают возможности нестандартного использования языка [Chesterman, 2016, p. 65] и реагируют на все появляющиеся в узусе тенденции и способствуют их закреплению.

Одной из таких тенденций выступает межъязыковая интерференция, связанная с 
глобальным статусом английского языка. В отличие от профессиональных переводчиков, «в сознании “наивных билингвов” при интенсивных контактах границы языков размываются, они неосознанно воспринимают языки как единую сущность, и “наивный перевод” принимает форму динамического “сближения" языков, “перетекания" языков друг в друга, адаптации» [Ривлина, 2018, с. 45]. Результатом такого процесса являются транслингвальные практики и гибридные тексты. Соответственно, формируются особые нормы ожидания, оказывающие влияние на характеристики межъязыкового перевода-процесса и переводов-результатов ("non-translations comprise part of the context of translations, as well as vice versa" [Toury, 2012, p. 85]).

В традиционном представлении переводчик осознанно противодействует межъязыковой интерференции [Мунэн, 1978]. В связи с этим особый интерес представляет изучение соотношения межъязыковой интерференции, переводческой интерференции, носящей характер универсалии [Mauranen, 2004], и трансференции в переводе - мотивированного отражения элементов языка оригинала в языке перевода (термин В.И. Черемисина, цит. по: [Умерова, 2003, с. 78]). Г. Тури считает интерференцию одним из законов перевода (Law of Interference), указывая, что при переводе феномены, определяющие организацию текста оригинала, чаще всего переносятся в текст перевода [Toury, 2012, p. 310]. Основания данного закона двойственны: они и когнитивные, и социокультурные. То, какую силу имеет данный закон в условиях конкретной коммуникативной ситуации, зависит от профессионализма переводчика и его опыта, а также от условий, в которых текст перевода порождается и воспринимается [Toury, 2012, p. 311], то есть от аспектов, характеризуемых понятием норм перевода.

М.А. Орёл, рассуждая о повышении переводимости в пределах пары «английский русский», фиксирует трансформацию конвенциональной ${ }^{2}$ нормы перевода: «...распространение в переводческой практике подходов и приемов, направленных на сохранение формально-структурных характеристик оригинальных текстов... является одновременно и следствием, и причиной сближения англий- ского и русского языков. Ряд русскоязычных текстов приобретают все больше иноязычных черт. Отличительные особенности некоторых разновидностей дискурса изменяются, что впоследствии оказывает влияние на ход и результат переводческого процесса» [Орёл, 2010 , с. 32]. Мы проиллюстриуем данное положение на примере дискурса отраслевых СМИ сферы ИТ и электроники.

Количественное исследование переводных и непереводных текстов, а также качественное сравнительное исследование оригиналов и переводов, в которых употребляются подобные гибриды, позволят нам вывить тенденции использования данных нестандартных единиц и охарактеризовать формирование «нормемы» (normeme) - частной нормы, которая должна рассматриваться в совокупности с рядом социокультурных факторов, вступающих в системное взаимодействие в изучаемом контексте [Toury, 2012, p. 89].

На предварительном этапе настоящего исследования ${ }^{3}$ мы провели сравнительный анализ оригиналов и переводов статей, опубликованных в отраслевом журнале «itWeek» (https://www.itweek.ru/) в 2016 году. В 17 рассмотренных статьях были использованы 53 термина, более 30 \% которых в переводе приобрели форму англо-русских гибридов, например low-code platforms low-code-nлатформы, CRM system - CRMсистема, wildcard certificates - wildcardсертификаты. Употребительность терминов такой структуры послужила причиной обращения к гибридам при изучении трансформации переводческой нормы в условиях «глобанглизации».

Сложные слова, «первая часть которых - иноязычная и пишется при этом латиницей, а вторая русская или также иноязычная, но пишущаяся кириллическим шрифтом», Л.П. Крысин именует метафорически - «слова-кентавры» [Крысин, 2010, с. 575]. Предмет нашего исследования наиболее точно определяется термином Е.П. Снеговой «сложные (дефисные) гибридные образования», толкуемые как «дефисные образования с первым компонентом - иноязычным словом или, гораздо чаще, иноязычной аббревиатурой» [Снегова, 2011, с. 643] (далее ДГО, гибриды). 
Спорным остается вопрос о включенности ДГО в лексическую систему русского языка и, соответственно, о нормативности употребления подобных единиц. Л.П. Крысин отмечает, что «слова-кентавры» - одно из свидетельств того, что язык не консервативен: он живо реагирует на изменяющуюся реальность, и в нем появляются не только новые номинации, но и новые модели, по которым эти номинации образуются [Крысин, 2010, с. 577]. По словам С.В. Друговейко-Должанской, «распространенность подобных образований и активность модели не позволяет нам отрицать их существование в лексической системе русского языка» (http://gramma.ru/RUS/?id=1.6). На основе данной модели создаются разнообразные единицы, в том числе терминологического характера, при этом подобные образования зачастую не зафиксированы словарями, и переводчику необходимо решать вопрос о допустимости употребления гибрида самостоятельно.

Мы обратились к трем крупным российским изданиям в сфере ИТ и электроники: «itWeek» (до 2018 г. - «РC Week»), «Computerworld» и «Новости электроники», публикующим как оригинальные статьи на русском языке, так и переводы с английского языка. На основе архива материалов за 2017 г. составлен корпус объемом 1155430 словоупотреблений (см. таблицу) ${ }^{4}$. В корпус вошли 859 непереводных статей и 448 переводных. В частотных списках подкорпусов автоматически отобраны 2762 англо-русских ДГО. Отметим, что все отобранные единицы соответствовали модели «иноязычный элемент + русскоязычная основа», образований с обратным порядком элементов не выявлено.
Посредством теста правдоподобия (loglikelihood, LL) определены некоторые значимые различия: при сравнении массивов переводных и непереводных статей как двух отдельных подкорпусов было отмечено, что авторы непереводных статей используют значительно больше гибридов, чем переводчики ( $\mathrm{LL}=104,36$, $p<0,05)$. Соответственно, межъязыковая интерференция в большей степени характерна для текстов, изначально написанных на русском языке, что свидетельствует о закреплении в узусе тенденции к употреблению гибридов.

Анализ частотного списка ДГО, представленных в переводных статьях, позволил обнаружить наиболее употребительные иноязычные элементы: Open Source- (52 примера), API- (42), 3D/2D- (34), IoT- (30), Linux- (27), PIN- (23), Windows- (19), SiC- (15), Bluetooth- (13), OLED- (13), SQL- (11), NoSQL- (10). Все 260 примеров использования данных популярных гибридов были сопоставлены с оригинальными контекстами на английском языке, а также с прецедентными переводами в словарях и вариантами в подкорпусе непереводных текстов, в результате чего в переводческих решениях выявлены определенные тенденции.

\section{Результаты и обсуждение}

Как показывает сравнительный анализ оригиналов и переводов, чаще всего гибрид появляется в переводе в результате калькирования аналитической конструкции, выраженной атрибутивно-именным сочетанием, что закономерно: IoT device - IoT-yстройство, 3D printer 3D-принтер, Linux company - Linux-компания (см. пример 1).

\section{Количественная характеристика подкорпусов Corpora characteristics}

\section{Quantitative Corpora characteristics}

\begin{tabular}{|l|c|c|c|}
\hline \multicolumn{1}{|c|}{ Название журнала } & $\begin{array}{c}\text { Количество } \\
\text { статей }\end{array}$ & $\begin{array}{c}\text { Общее количество } \\
\text { словоупотреблений }\end{array}$ & $\begin{array}{c}\text { Количество } \\
\text { словоупотреблений } \\
\text { гибридов }\end{array}$ \\
\hline \multicolumn{4}{|c|}{ Подкорпус непереводных материалов } \\
\hline «it Week» & 522 & 332547 & 738 \\
\hline «Computerworld» & 243 & 202710 & 174 \\
\hline «Новости электроники» & 94 & 279784 & 33 \\
\hline \multicolumn{3}{|c|}{ Подкорпус переводных материалов } \\
\hline «itWeek» & 170 & 131090 & 90 \\
\hline «Соmputerworld» & 249 & 156626 & 152 \\
\hline «Новости электроники» & 29 & 52673 & 335 \\
\hline
\end{tabular}


Пример 1

\begin{tabular}{|l|l|}
\hline \multicolumn{1}{|c|}{ Оригинал } & \multicolumn{1}{|c|}{ Перевод } \\
\hline $\begin{array}{l}\text { In addition, Vertica 9 natively integrates with key eco- } \\
\text { system technologies and open source innovation, in- }\end{array}$ & $\begin{array}{l}\text { В дополнение к этому Vertica 9 естественным обра- } \\
\text { зом интегрируется с ключевыми экосистемными } \\
\text { cluding Microsoft PowerBI, Cloudera Manager and } \\
\text { Apache Spark 2.1. }\end{array}$ \\
$\begin{array}{l}\text { You can also run popular open-source programming } \\
\text { чая Microsoft PowerBI, Cloudera Manager и Apache } \\
\text { languages such as python, perl, ruby, php, and gcc. }\end{array}$ & $\begin{array}{l}\text { Вы также можете работать с популярными Ореп } \\
\text { Source-языками программирования, такими как } \\
\text { Python, Perl, Ruby, РНР и GCС. }\end{array}$ \\
\hline
\end{tabular}

Как видим в примере 1, зачастую калькируется цепочка лексем.

Одним из наблюдаемых переводческих приемов является также лексическое добавление: иноязычный элемент соединяется с русскоязычным словом, которое чаще всего называет родовое понятие или поясняет смысл иноязычного элемента в контексте (3D - 3D-модуль, PIN - PIN-код).

Так, в примере 2 переводчик использует модель при совершении грамматической трансформации: $3 D$ выступает в качестве определяющего элемента к слову имитация, которое появилось в результате замены глагола simulate.

Тенденцией в переводческих решениях выступает закрепление сочетаемости: иноязычный элемент используется с русскоязычной основой (зачастую она является калькой традиционной англоязычной сочетаемости), хотя в оригинале этой основы нет (пример 3).

Особый исследовательский интерес вызывают переводы, в которых гибриды употребляются по инициативе переводчика.

Так, в примере 4 проявляется свобода переводчика в использовании гибридной мо-

Пример 2

\begin{tabular}{|l|l|}
\hline \multicolumn{1}{|c|}{ Оригинал } & \multicolumn{1}{|c|}{ Перевод } \\
\hline While headgear is typically required, Bajarin said one of & Хотя здесь обычно требуются специальные очки или \\
the most impressive VR demos he's seen simulates a & шлем, он назвал одной из самых впечатляющих из ви- \\
heart surgery procedure in 3D by a company called & денных им VR-демонстраций 3D-имитацию процесса \\
zSpace. & операции на сердце, созданную компанией zSpace. \\
\hline
\end{tabular}

\section{Пример 3}

\begin{tabular}{|l|l|}
\hline \multicolumn{1}{|c|}{ Оригинал } & \multicolumn{1}{|c|}{ Перевод } \\
\hline $\begin{array}{l}\text { OLED screens began appearing in smartphones several } \\
\text { years ago and are used today in phones from Samsung, } \\
\text { LG, and other competitors. }\end{array}$ & $\begin{array}{l}\text { OLED-экраны начали появляться в смартфонах } \\
\text { ещескольо лет назад, ими снабжены сегодня те- } \\
\text { лефоны Samsung, LG и ряда других производителей. }\end{array}$ \\
\hline $\begin{array}{l}\text { Now that Apple has finally released its home button-less } \\
\text { OLED iPhone that's been rumored for years, we can } \\
\text { start focusing on what's inside the phone. }\end{array}$ & $\begin{array}{l}\text { Tеперь, когда Apple наконец выпустила iPhone с } \\
\text { ОLED-экраном, слухи о котором ходили долгие } \\
\text { годы, компания может сосредоточиться на том, что } \\
\text { находится внутри устройства. }\end{array}$ \\
\hline
\end{tabular}

\section{Пример 4}

\begin{tabular}{|c|c|c|}
\hline Оригинал & Перевод 1 & Перевод 2 \\
\hline $\begin{array}{l}\text { Oracle has reportedly made a new } \\
\text { round of staff cuts to its Solaris and } \\
\text { SPARC (Scalable Processor Archi- } \\
\text { tecture) businesses. }\end{array}$ & $\begin{array}{l}\text { Корпорация Oracle, по слухам, } \\
\text { приступила к очередному раунду } \\
\text { сокращения персонала, занимаю- } \\
\text { щегося OC Solaris и процессорной } \\
\text { RISC-архитектурой SPARC. }\end{array}$ & $\begin{array}{l}\text { Корпорация Oracle, по слухам, } \\
\text { приступила к очередному раунду } \\
\text { сокращения персонала, занимаю- } \\
\text { щегося направлениями, связанны- } \\
\text { ми с операционной системой } \\
\text { Solaris и архитектурой RISC- } \\
\text { процессоров SPARC. }\end{array}$ \\
\hline
\end{tabular}


дели как инструмента. Переводчик на основе собственных фоновых знаний эксплицирует термин Scalable Processor Architecture. В оригинале нет ни аббревиатуры RISC, ни расшифровки [RISC (англ. reduced instruction set computer - компьютер с набором коротких (простых, быстрых) команд)]. Термин RISC зафиксирован в большом количестве словарей и имеет несколько аналогов: процессор (микропрочессор) с упрощенным (сокращенным) набором команд, ЭВМ с сокращенным набором команд (СТП). Оба используемых переводчиком ДГО - RISC-apхитектура и RISC-nроиессор - закреплены в словарях, как англо-русских, так и специальных одноязычных.

В примере 5 в оригинале дважды используется аббревиатура IoT (англ. internet of things). Переводчик не калькирует конструкцию полностью, а, исходя из контекста и используя фоновые знания, добавляет русскоязычную основу, чтобы разграничить два понятия в одном предложении и сделать перевод более прозрачным.

Таким образом, установлены тенденции, характеризующие как проявления переводческой и межъязыковой интерференции, так и трансференции в переводе. Рассмотрим обнаруженные тенденции в социокультурном контексте, в котором осуществляется перевод и рецепция анализируемого материала.

Издания «itWeek», «Computerworld» и «Новости электроники» можно охарактеризовать как бизнес-СМИ - деловые специализированные журналы, освещающие события отечественного и мирового рынков ИТ и электронных компонентов. Издания имеют печатные и онлайн-версии (в статье мы не затрагиваем аспект гипертекстуальности и связанных с ней предпосылок употребления неадаптированных заимствований). Целевая аудитория журналов составляет несколько групп реципиентов-специалистов: руководители
ИТ-подразделений предприятий и топ-менеджеры по развитию бизнеса, разработчики программного обеспечения, дистрибьюторы ИТ-продукции (https://www.itweek.ru/); ИТ-менеджеры информационных служб предприятий различных отраслей (https://www.osp.ru/cw/); разработчики электронной техники, руководители конструкторских и проектных отделов (https://www.compel.ru/lib/ne/2019). Перечисленные характеристики позволяют нам причислить рассматриваемые издания к категории качественной прессы.

Переводные статьи в этих журналах чаще всего не обозначены как таковые: они не выделены в самостоятельный раздел, не имеют ключевого слова «перевод» в метаданных, не снабжаются гиперссылкой на текст оригинала (за редким исключением), не имеют указаний на имя переводчика. Таким образом, отличить переводы от статей, изначально написанных на русском языке, можно только по транскрибированному иноязычному имени автора статьи, и редакция не подразумевает, что реципиент будет сравнивать оригинал и перевод. Именно поэтому можно говорить о принадлежности рассматриваемых переводов к категории «скрытых» (covert translation) - переводов-инструментов, которые, по определению Ю. Хаус, визуально и функционально не отличаются от текстов, изначально созданных на языке перевода (подробнее о концепции Ю. Хаус см.: [Прунч, 2015, с. 204]).

По словам редактора журнала «itWeek», редакция сотрудничает с переводчиками-профессионалами, имеющими определенные знания в области ИТ (https://www.itweek.ru/about/ faq/). Редакции необходим качественный, четкий и грамотный перевод: даже при работе с внештатными переводчиками к их материалам предъявляются строгие требования в отношении стиля и объема. Переводчик в сфере ИТ может не быть программистом. Одна-

\section{Пример 5}

\begin{tabular}{|l|l|}
\hline \multicolumn{1}{|c|}{ Оригинал } & \multicolumn{1}{|c|}{ Перевод } \\
\hline Dell is contributing its Fuse IoT code base as the initial & В качестве программной основы для него компа- \\
code for EdgeX Foundry, providing an open framework & $\begin{array}{l}\text { ния Dell предоставила базу исходного кода своего } \\
\text { for IoT interoperability. }\end{array}$ \\
& $\begin{array}{l}\text { обт-проекта Fuse - открытого фреймворка для } \\
\text { личных ІоТ-устройств. }\end{array}$ \\
\hline
\end{tabular}


ко, как отмечает Е. Бартов, руководитель ГК «Альянс ПРО» - бюро рекламно-технических англо-русских переводов для ИТ-компаний, переводчик должен понимать: «а) как мыслит его (переводчика) целевая аудитория; б) как работает переводимый продукт; в) что реально имел в виду автор» (https://tran.su/ tehnicheskij-perevod/). Переводчик начинает освоение предметной области с изучения параллельных текстов, прецедентных переводов, существующих рекомендаций коллег и предпочтений заказчика. Результатом этого процесса становится специализация переводческого габитуса и регистрация соответствующих норм, необходимых для производства текста перевода в условиях конкретной переводческой задачи.

В русскоязычном непереводном дискурсе отраслевых медиа сферы ИТ употребляются многочисленные вариативные эквиваленты англоязычной компьютерной терминологии. По замечанию А.Б. Кутузова, помимо семантических эквивалентов (сеть, данные, маршрутизатор), калькированных конструкций (application server - сервер приложений, hyperlink - гиперссылка, peеr 2 peer каждый-с-каждым) и заимствований через транскрипцию (принтер, сканер, файл), в текстах компьютерной тематики традиционно используются неадаптированные единицы в латинской графике (названия корпораций, технологические стандарты и названия программных продуктов, например Nvidia, AMD, Novell, Microsoft, Intel и др.) [Кутузов, 2007]. А.Б. Кутузов приводит рекомендуемый алгоритм работы переводчика с компьютерной терминологией, в котором отражена непосредственная подчиненность практики перевода полю рецепции: следует проверить, не относится ли термин к группе непереводимых; если нет, выяснить, существует ли уже устоявшийся в сообществе вариант перевода этого термина (не стоит предлагать компьютерному сообществу изменить сложившееся для того или иного объекта название); в маловероятном случае, когда традиционного эквивалента еще не появилось, переводчик вправе самостоятельно выбирать способ перевода [Кутузов, 2007].

Представленные в нашем исследовании примеры перевода и множество других при- меров современной переводческой практики показывают, что в контексте глобализации как интерференция, так и трансференция в переводе допустимы. Они определяются нормой ожидания. Язык СМИ в области ИТ и электроники - во многом продукт «глобального языкового метаболизма» (термин С.В. Власенко [Власенко, 2008]), результата становления транслингвального пространства и господства английского языка как lingua franca в сфере инноваций и технического прогресса.

\section{Выводы}

Наиболее частотные иноязычные элементы, используемые переводчиком в ДГО, названия корпораций, технологические стандарты, названия программных продуктов, аббревиатуры, названия определенных компонентов операционных систем и т. д. (Open Source, $A P I$, IoT, Linux, OLED и др.) - можно отнести к группе непереводимых (по А.Б. Кутузову). Большинство гибридов в переводных текстах образовано путем калькирования аналитической конструкции языка оригинала: иногда, несмотря на существующие русскоязычные аналоги, в том числе закрепленные в словарях, переводчики используют уже существующие ДГО или создают их сами. Зачастую, даже если в оригинале нет непосредственного эквивалента ДГО, переводчик считает необходимым его использование. Плотность гибридных образований в переводных текстах не столь велика, как в непереводных, что может объясняться сознательным противостоянием интерференции со стороны переводчика. Однако сопоставительное исследование оригиналов и переводов показывает обратное - ориентацию на трансференцию (использование гибрида как инструмента, эффективно воплощающего номинативную функцию и экономящего речевые усилия). Интерференция в переводе очевидна, но ее природа меняется. Различия между переводными и непереводными текстами стираются, а переводчик участвует в формировании языковой и переводческой нормы.

Создавая новый гибрид, переводчик осуществляет компрессию смысла, ориентируясь как на сложившуюся традицию, функциональный билингвизм / диграфию потенциального 
реципиента, так и на его специальные знания. Уместное в ситуации перевода употребление гибрида, на наш взгляд, позволяет говорить о высокой специализации (или «тонкой настройке») лингвистического и профессионального габитуса переводчика, или, другими словами, о сформированности «интралингвальности»компетенции «медиатора социального взаимодействия посредством текстов» [Овчинникова, Павлова, 2016, с. 268].

Трансформация практики англо-русского перевода в условиях глобального языкового метаболизма - сложный объект, требующий комплексного, системного изучения. Проведенное нами исследование, безусловно, носит частный характер, однако в нем достигнута поставленная цель: на примере гибридных образований мы проследили, как формируется норма ожидания и как характер непереводного дискурса оказывает влияние на практику перевода. В качестве перспектив работы обозначим выявление дополнительных факторов, детерминирующих формирование нормы перевода бизнес-СМИ рассмотренной тематики. Для этого необходимо провести анализ характеристик ДГО, используемых в переводном и непереводном дискурсах; описать особенности рецепции переводных и непереводных материалов, содержащих ДГО; изучить переводческий процесс и этапы работы с текстом в редакции журналов на основе наблюдения и интервью.

\section{ПРИМЕЧАНИЯ}

${ }^{1}$ Статья подготовлена в рамках выполнения государственного задания МОиН РФ по проекту № 34.6111.2017/БЧ «Медиаперевод в современных информационных условиях».

The research is carried out within the framework of Ministry of Science and Higher Education of the Russian Federation state assignment, project no. 34.6111.2017/BCHTranslating media texts within the context of modern tendencies in mass communication.

${ }^{2}$ В понимании В.Н. Комиссарова, конвенциональная норма - аспект переводческой нормы, заключающий в себе взгляды на цели и задачи перевода и пути достижения этих целей, принятые в языковом коллективе на определенном историческом этапе [Комиссаров, 1990, с. 229].

${ }^{3}$ В исследовании использованы материалы выпускной квалификационной работы, выполнен- ной студенткой Челябинского государственного университета В.Д. Аристовой под научным руководством Е.С. Краснопеевой.

${ }^{4}$ Программное обеспечение, использованное в исследовании: WebBootCat (M. Baroni and S. Bernardini. 2004. BootCaT: Bootstrapping corpora and terms from the web. Proceedings of LREC 2004; https://bootcat.dipintra.it/); AntConc (L. Anthony; https://www.laurenceanthony.net/software/antconc/); UCREL log-likelihood wizard (P. Rayson; http:// corpora.lancs.ac.uk/clmtp/2-stat.php); Microsoft Excel 2007 (https://products.office.com/en-us/previousversions/microsoft-excel-2007).

\section{СПИСОК ЛИТЕРАТУРЫ}

Аджемова А., Гарстенауэр Т., 2017. «Бум» англицизмов в современном деловом дискурce // Корпоративная коммуникация в России: дискурсивный анализ : коллектив. моногр. / отв. ред. Т. А. Милехина, Р. Ратмайр. М. : ЯСК. С. 173-184.

Анненкова И. В., 2008. Принципы использования латинской графики в СМИ // Мир русского слова. № 3. С. 41-47.

Власенко С. В., 2008. Адаптивность русского как переводящего языка в англо-русском коммуникативном взаимодействии с позиций переводоведения // Язык, сознание, коммуникация : сб. ст. / отв. ред. В. В. Красных, А. И. Изотов. М. : МАКС Пресс. Вып. 36. С. 70-82.

Гриценко Е. С., Ненашева Т. А., 2017. Индексальный потенциал английского языка в русскоязычном коммуникативном пространстве // Вопросы психолингвистики. № 3. С. 32-47.

Загидуллина М. В., 2018. Панмедиатизация как основа ментально-языковых трансформаций // Ментально-языковые трансформации русской лингвокультурной личности: поиск идентичности в медиатизированном обществе : коллектив. моногр. / науч. ред. М. В. Загидуллина. Челябинск : Изд-во Челяб. гос. ун-та. С. 41-79.

Кирилина А. В., 2011. Перевод и языковое сознание в динамической синхронии: психические границы языка (на материале русского языка Москвы) // Вопросы психолингвистики. № 13. С. 30-39.

Комиссаров В. Н., 1990. Теория перевода: лингвистические аспекты. М. : Высш. шк. 253 с.

Крысин Л. П., 2010. О некоторых новых типах слов в русском языке: слова-«кентавры» // Вестник Нижегородского университета им. Н.И. Лобачевского. № 4 (2). С. 575-579.

Кутузов А. Б., 2007. Пролегомены к денотативной модели перевода компьютерных терми- 
нов // Languages and Literatures. № 22. URL: https://web.archive.org/web/20130201020331/ http://frgf.utmn.ru/mag/22/46.

Мунэн Ж., 1978. Теоретические проблемы перевода. Перевод как языковой контакт // Вопросы теории перевода в зарубежной лингвистике / вступ. ст. и общ. ред. В. Н. Комиссарова. М. : Междунар. отношения. С. 36-41.

Овчинникова И. Г., Павлова А. В., 2016. Переводческий билингвизм. По материалам ошибок письменного перевода. М. : Флинта. 304 с.

Орёл М. А., 2008. Перевод с английского на англорусский, или Кто виноват и что делать? // Вестник Нижегородского государственного лингвистического университета им. Н.А. Добролюбова. Вып. 4. Лингвистика и межкультурная коммуникация. С. 87-97.

Орёл М. А., 2010. Перевести нельзя перенести (Часть вторая) // МОСТЫ. № 3 (27). С. 29-33.

Прошина 3. Г., 2017. Транслингвизм и его прикладное значение // Вестник Российского университета дружбы народов. Серия: Вопросы образования : Языки и специальность. № 2. С. 155-170.

Прунч Э., 2015. Пути развития западного переводоведения. От языковой асимметрии к политической. М. : Р. Валент. 512 с.

Ривлина А. А., 2018. Перевод в эпоху глобализации английского языка и усиления транслингвальной практики // Социальные и гуманитарные науки на Дальнем Востоке. Т. 15, № 1. С. 43-49.

Снегова Е. П., 2011. О лексикографическом представлении сложносоставных слов с иноязычным компонентом // Вестник Нижегородского университета им. Н.И. Лобачевского. № 6. C. 643-646.

Тюленев С. В., 2004. Теория перевода. М. : Гардарики. $336 \mathrm{c}$.

Тюленев С. В., 2012. Что перевод системе? Что ему она? // Логос. № 3 (87). С. 106-130.

Умерова М. В., 2003. Лингвистический статус языка переводов : дис. ... канд. филол. наук. М. $279 \mathrm{c}$.

Albl-Mikasa M., 2017. ELF and Translation / Interpreting // The Routledge Handbook of English as a Lingua Franca / ed. by J. Jenkins, W. Bake, M. Dewey. L. ; N. Y. : Routledge. P. 369-384.

Bourdieu P., Wacquant L. J. D., 1992. An Invitation to Reflexive Sociology. Chicago : The University of Chicago Press. 332 p.

Chesterman A., 2016. Memes of Translation. The Spread of Ideas in Translation Theory. Amsterdam ; Philadelphia : John Benjamins Publishing Company. $225 \mathrm{p}$.

García O., Wei L., 2014. Translanguaging: Language, Bilingualism and Education. Palgrave Macmillan. 176p. DOI: $10.1057 / 9781137385765$.
Grin F., 2017. Translation and Language Policy in the Dynamics of Multilingualism // International Journal of the Sociology of Language. № 243. P. 155-181. DOI: 10.1515/ijsl-2016-005.

Krasnopeyeva E., 2018. Understanding the Dynamics of User-Generated Translation on YouTube: A Bourdieusian Perspective // New Voices in Translation Studies. № 18. P. 38-83.

Mauranen A., 2004. Corpora, Universals and Interference // Translation Universals : Do They Exist? Amsterdam ; Philadelphia : John Benjamins Publishing Company. P. 15-33.

Remkhe I., Nefedova L., Gillespie D., 2017. Rethinking the Translator's Role Within the GILT Project: An Integrated Approach // Russian Journal of Linguistics. № 21 (4). P. 910-926. DOI: 10.22363/ 2312-9182-2017-21-4-910-926.

Simeoni D., 1998. The Pivotal Status of the Translator's Habitus // Target. № 10(1). P. 1-39. DOI: 10.1075/ target.10.1.02sim.

Toury G., 2012. Descriptive Translation Studies and Beyond. Amsterdam ; Philadelphia : John Benjamins Publishing Company. 350 p. DOI: 10.1075/btl.100.

Tyulenev S., 2014. Translation and Society. L. ; N. Y. : Routledge. 210 p. DOI: 10.4324/9781315775593.

Varis P., Wang X., 2011. Superdiversity on the Internet : A Case from China // Diversities. Vol. 13, № 2. P. 71-83.

\section{СЛОВАРЬ}

СТП - Справочник технического переводчика // Интент. Инженерная переводческая компания. URL: http://intent.gigatran.com.

\section{REFERENCES}

Adzhemova A., Garstenauer T., 2017. «Bum» anglitsizmov v sovremennom delovom diskurse [Influx of Anglicisms in Modern Business Discourse]. Milekhina T.A., Ratmayrz R., eds. Korporativnaya kommunikatsiya $v$ Rossii: diskursivnyy analiz: kollektiv. monogr. [Corporate Communication in Russia: Discourse Analysis. Collective Monograph]. Moscow, YaSK Publ., pp. 173-184.

Annenkova I.V., 2008. Printsipy ispolzovaniya latinskoy grafiki v SMI [Principles of Latin Script Usage in Media]. Mir russkogo slova [The World of Russian Word Journal], no. 3, pp. 41-47.

Vlasenko S.V., 2008. Adaptivnost russkogo kak perevodyashchego yazyka $\mathrm{v}$ anglo-russkom kommunikativnom vzaimodeystvii s pozitsiy 
perevodovedeniya [Adaptability of the Russian Language as a Target Language in EnglishRussian Communication from the Perspective of Translation Studies]. Krasnykh V.V., Izotov A.I., eds.Yazyk, soznanie, kommunikatsiya: sb. st. [Language, Consciousness, Communication. Collection of Articles]. Moscow, MAKS Press, iss. 36, pp. 70-82.

Gritsenko E.S., Nenasheva T.A., 2017. Indeksalnyy potentsial angliyskogo yazyka v russkoyazychnom kommunikativnom prostranstve [Indexical Capacities of English in Russian-Based Communication]. Voprosy psikholingvistiki [Journal of Psycholinguistics], no. 3, pp. 32-47.

Zagidullina M.V., 2018. Panmediatizatsiya kak osnova mentalno-yazykovykh transformatsiy [PanMediatization as the Basis of Mental-Linguistic Transformations]. Mentalno-yazykovye transformatsii russkoy lingvokulturnoy lichnosti: poisk identichnosti $v$ mediatizirovannom obshchestve: kollektiv. monogr. [MentalLinguistic Transformations of Russian Linguocultural Personality: In Search for Identity in Mediatized Society. Collective Monograph]. Chelyabinsk, Izd-vo Chelyabinskogo gosudarstvennogo universiteta, pp. 41-79.

Kirilina A.V., 2011. Perevod i yazykovoe soznanie v dinamicheskoy sinkhronii: psikhicheskie granitsy yazyka (na materiale russkogo yazyka Moskvy [Translation / Interpretation and the Language in the Dynamic Synchrony: The Mental Boundaries of the Languages (On the Material of Russian in Moscow)]. Voprosy psikholingvistiki [Journal of Psycholinguistics], no. 13, pp. 30-39.

Komissarov V.N., 1990. Teoriya perevoda: lingvisticheskie aspekty [Theory of Translation: Linguistic Aspects]. Moscow, Vysshaya shkola Publ. 253 p.

Krysin L.P., 2010. O nekotorykh novykh tipakh slov v russkom yazyke: slova-"kentavry" [On Some New Types of Words in Russian Language: "Centaur-Words"]. Vestnik Nizhegorodskogo universiteta im. N.I. Lobachevskogo [Vestnik of Lobachevsky University of Nizhni Novgorod], no. 4 (2), pp. 575-579.

Kutuzov A.B., 2007. Prolegomeny k denotativnoy modeli perevoda kompyuternykh terminov [Prolegomena to Denotational Model of Translation of Computer Terms]. Languages and Literatures, no. 22. URL: https:// web.archive.org/web/20130201020331/http:// frgf.utmn.ru/mag/22/46.

Mounin G., 1978. Teoreticheskie problemy perevoda. Perevod kak yazykovoy kontakt [Theoretical Issues of Translation. Translation as Language
Contact]. Komissarov V.N., ed. Voprosy teorii perevoda $v$ zarubezhnoy lingvistike [Theoretical Issues of Translation in Foreign Linguistics]. Moscow, Mezhdunarodnye otnosheniya Publ., pp. 36-41.

Ovchinnikova I.G., Pavlova A.V., 2016. Perevodcheskiy bilingvizm. Po materialam oshibok pismennogo perevoda [Translational Bilingualism. The Issue of Errors in Translation]. Moscow, Flinta Publ. 304 p.

Oryol M.A., 2008. Perevod s angliyskogo na anglorusskiy, ili Kto vinovat i chto delat? [Translation from English to Russian-English. Who to Blame and What to Do?]. Vestnik Nizhegorodskogo gosudarstvennogo lingvisticheskogo universiteta im. N.A. Dobrolyubova [Nizhny Novgorod Linguistics University Bulletin], iss. 4, pp. 87-97.

Oryol M.A., 2010. Perevesti nelzya perenesti (Chast vtoraya) [To Translate or to Transfer. Part Two]. MOSTY[Bridges], no. 3 (27), pp. 29-33.

Proshina Z.G., 2017. Translingvizm i ego prikladnoe znachenie [Translingualism and Its Application]. Vestnik Rossiyskogo universiteta druzhby narodov. Seriya: Voprosy obrazovaniya. Yazyki $i$ spetsialnost [RUDN Journal of Language and Translingual Practices], no. 2, pp. 155-170.

Prunch E., 2015. Puti razvitiya zapadnogo perevodovedeniya. Ot yazykovoy asimmetrii $k$ politicheskoy [The Directions of Development of Western Translation Studies. From Language Asymmetry to Political Asymmetry]. Moscow, R. Valent Publ. 512 p.

Rivlina A.A., 2018. Perevod v epokhu globalizatsii angliyskogo yazyka i usileniya translingvalnoy praktiki [Translation in the Era of English Language Globalization and Emergence of Translingualism]. Sotsialnye i gumanitarnye nauki na Dalnem Vostoke, vol. 15, no. 1, pp. 43-49.

Snegova E.P., 2011. O leksikograficheskom predstavlenii slozhnosostavnykh slov s inoyazychnym komponentom [On Lexicography of Compound Words with Borrowed Components]. Vestnik Nizhegorodskogo universiteta im. N.I. Lobachevskogo [Vestnik of Lobachevsky University of Nizhni Novgorod], no. 6, pp. 643-646.

Tyulenev S.V., 2004. Teoriya perevoda [Theory of Translation]. Moscow, Gardariki Publ. 336 p.

Tyulenev S.V., 2012. Chto perevod sisteme? Chto emu ona? [What Is the Relation of Translation to the System? What Is the Relation of the System to Translation?]. Logos, no. 3 (87), pp. 106-130.

Umerova M.V., 2003. Lingvisticheskiy status yazyka perevodov: dis. ... kand. filol. nauk [Linguistic Status of the Language of Translation. Cand. philol. sci. diss.]. Moscow. 279 p. 
Albl-Mikasa M., 2017. ELF and Translation / Interpreting. Jenkins J., Bake W., Dewey M., eds. The Routledge Handbook of English as a Lingua Franca. London, New York, Routledge, pp. 369-384.

Bourdieu P., Wacquant L.J.D., 1992. An Invitation to Reflexive Sociology. Chicago, The University of Chicago Press. 332 p.

Chesterman A., 2016. Memes of Translation. The Spread of Ideas in Translation Theory. Amsterdam, Philadelphia, John Benjamins Publishing Company. 225 p.

García O., Wei L., 2014. Translanguaging: Language, Bilingualism and Education. Palgrave Macmillan. 176 p. DOI: 10.1057/9781137385765.

Grin F., 2017. Translation and Language Policy in the Dynamics of Multilingualism. International Journal of the Sociology of Language, no. 243, pp. 155-181. DOI: 10.1515/ijsl-2016-005.

Krasnopeyeva E., 2018. Understanding the Dynamics of User-Generated Translation on YouTube: A Bourdieusian Perspective. New Voices in Translation Studies, no. 18, pp. 38-83.

Mauranen A., 2004. Corpora, Universals and Interference. Translation Universals: Do They Exist? Amsterdam, Philadelphia, John Benjamins Publishing Company, pp. 15-33.
Remkhe I., Nefedova L., Gillespie D., 2017. Rethinking the Translators Role Within the GILT Project: An Integrated Approach. Russian Journal of Linguistics, no. 21 (4), pp. 910-926. DOI: 10.22363/2312-9182-2017-21-4-910-926.

Simeoni D., 1998. The Pivotal Status of the Translators Habitus. Target, no. 10 (1), pp. 1-39. DOI: 10.1075/ target.10.1.02sim.

Toury G., 2012. Descriptive Translation Studies and Beyond. 2nd ed. Amsterdam, Philadelphia, John Benjamins Publishing Company. 350 p. DOI: 10.1075/btl.100.

Tyulenev S., 2014. Translation and Society. London, New York, Routledge. 210 p. DOI: 10.4324/ 9781315775593

Varis P., Wang X., 2011. Superdiversity on the Internet: A Case from China. Diversities, vol. 13, no. 2, pp. 71-83.

\section{DICTIONARY}

Spravochnik tehnicheskogo perevodchika [Technical Translator's Guide]. Intent. Inzhenernaya perevodcheskaya kompaniya [Intent. Engineering Translation Company]. URL: http:/ /intent.gigatran.com/.

\section{Information About the Authors}

Liliya A. Nefedova, Doctor of Sciences (Philology), Professor, Dean of the Faculty of Linguistics and Translation, Chelyabinsk State University, Bratyev Kashirinykh St, 129, 454001 Chelyabinsk, Russia, lan2@mail.ru, https://orcid.org/0000-0003-3105-766X

Ekaterina S. Krasnopeyeva, Candidate of Sciences (Philology), Associate Professor, Department of Theory and Practice of Translation, Chelyabinsk State University, Bratyev Kashirinykh St, 129, 454001 Chelyabinsk, Russia, ye.kr121csu@gmail.com, https://orcid.org/0000-0002-3503-1849

\section{Информация об авторах}

Лилия Амиряновна Нефёдова, доктор филологических наук, профессор, декан факультета лингвистики и перевода, Челябинский государственный университет, ул. Братьев Кашириных, 129, 454001 г. Челябинск, Россия, lan2@mail.ru, https://orcid.org/0000-0003-3105-766X

Екатерина Сергеевна Краснопеева, кандидат филологических наук, доцент кафедры теории и практики перевода, Челябинский государственный университет, ул. Братьев Кашириных, 129, 454001 г. Челябинск, Россия, ye.kr121csu@gmail.com, https://orcid.org/0000-0002-3503-1849 